\title{
Modelling of Coke Layer Collapse during Ore Charging in Ironmaking Blast Furnace by DEM
}

\author{
Yoichi Narita $^{1, *}$, Hiroshi Mio ${ }^{1}$, Takashi Orimoto ${ }^{1}$ and Seiji Nomura $^{1}$ \\ ${ }^{1}$ Process Research Laboratories, Nippon Steel and Sumitomo Metal Corporation. Futtsu, Chiba 293-8511, Japan
}

\begin{abstract}
A technical issue in an ironmaking blast furnace operation is to realize the optimum layer thickness and the radial distribution of burden (ore and coke) to enhance its efficiency and productivity. When ore particles are charged onto the already-embedded coke layer, the coke layer-collapse phenomenon occurs. The coke layer-collapse phenomenon has a significant effect on the distribution of ore and coke layer thickness in the radial direction. In this paper, the mechanical properties of coke packed bed under ore charging were investigated by the impact-loading test and the large-scale direct shear test. Experimental results show that the coke particle is broken by the impact force of ore charging, and the particle breakage leads to weaken of coke-layer strength. The expression of contact force for coke in Discrete Element Method (DEM) was modified based on the measured data, and it followed by the 1/3-scaled experiment on coke's collapse phenomena. Comparing a simulation by modified model to the $1 / 3$-scaled experiment, they agreed well in the burden distribution.
\end{abstract}

\section{Introduction}

A blast furnace is a huge reactor used for reducing and smelling iron ore to produce pig iron. Coke and ore particles are supplied through the top of the furnace and stacked alternately in layers. A hot air is blown into the lower section of the furnace, reacts with coke to generate carbon monoxide, which reduces iron ore. Thus, the gas flow distribution has strong influence to efficiency and productivity of blast furnace. To control the gas flow, optimizing the burden distribution is very important. However, a coke layer-collapse occurs during ore charging onto the inclined coke bed because of the density difference between them. The coke particles have about three times less density than that of ore particles. This coke layer-collapse affects to the burden distribution and ore to coke layer thickness ratio. Furthermore, in the actual blast furnace, the coke layer thickness after collapse cannot be measured because the coke layer is covered with ore layer. Since many experimental studies have been carried out to investigate the coke collapse and clarify dominant factors [1-6]. Some studies have used numerical method like Discrete Element Method (DEM)[7] for better understanding of the phenomena involved. DEM can provide deeper insight on the particle flow [8], but the mechanics of coke packed bed has not been fully analyzed yet, because the bed has peculiar mechanical properties. A large number of investigations have been published on the mechanical properties of geomaterials, which consist of various shape of particles such as rounded rock, crushed stone, sea sand and so on. Especially, packed bed of volcanic coarse-grained soil, which is mainly formed from pumice particles, has peculiar mechanical properties. The shear resistance angle of packed bed is significantly reduced with the increase of isotropic consolidation stress due to the particle breakage [9-10].

In this study, three kinds of experiment were carried out to investigate the influence of particle breakage on coke collapse. First, the particle breakage and stress on its packed bed under ore charging were measured by an impact loading test. Second, the shear resistance angle under compressive stress was measured by a large-scale direct shear test. Third, a scaled model experiment of ore charging onto blast furnace was carried out to measure the coke collapse. The characteristic of coke particle and coke packed bed under stress were discussed. The contact model of DEM was modified on the basis of the experimental result to improve estimation accuracy in coke collapse.

\section{Experiments}

\subsection{Impact-loading test}

Fig.1 shows a schematic illustration of the impactloading test. $10 \mathrm{~kg}$ of coke particles having $15-20 \mathrm{~mm}$ diameter was put into a sampling box. The sampling box has a cylindrical shape of $600 \mathrm{~mm}$ diameter. $75 \mathrm{~kg}$ of sinter particle having $10-15 \mathrm{~mm}$ was charged from a hopper, which is $6300 \mathrm{~mm}$ above the bottom of the sampling box. A pressure measurement film (Prescale LW, Fujifilm Business Supply Co.) was stuck to the inner bottom of the sampling box to measure the impact force acting on coke packed bed bottom. After the test,

Corresponding author: narita.58d.yoichi@.jp.nssmc.com 
coke and ore were taken out from the sampling box. The particle size distribution was measured, and mass fraction of broken coke particle $(<15 \mathrm{~mm})$ was obtained. The pressure measurement film was analyzed by the digital analysis system (FPD-9210, Fujifilm Business Supply Co.) to calculate the area receiving a stress of $4 \mathrm{MPa}$, tensile strength of coke[11], or more.

\subsection{Large-scale direct shear test}

Fig. 2 shows a schematic illustration of the large-scale direct shear test apparatus. The shear box is $400 \mathrm{~mm}$ cube. The experimental conditions are tabulated in Table 1. Coke particles having $19-75 \mathrm{~mm}$ in diameter was poured into the shear box. The shear box can be divided into upper and lower parts. The upper part is free to move in the vertical direction, and the lower part is free to move in the horizontal direction. The top plate was placed on the sample. When a normal load was applied vertically to the top plate, the particles were constricted and the top plate sank gradually. After the constriction was settled, a shear load was applied. The shear load was controlled to retain the displacing speed of lower part at a target speed. The vertical displacement of the top plate and the shear load was recorded during shearing. The shear resistance angle $\phi_{\mathrm{r}}$ was calculated by the following equation.

$$
\phi_{\mathrm{r}}=\sigma_{\mathrm{s}, \max } / \sigma_{\mathrm{n}}
$$

where $\sigma_{\mathrm{s}, \max }$ and $\sigma_{\mathrm{n}}$ are the maximum shear stress and the normal stress, respectively. After the shear test, coke was taken out from the shear box. The particle size distribution was measured, and the mass fraction of small particle $(<19 \mathrm{~mm})$ was obtained

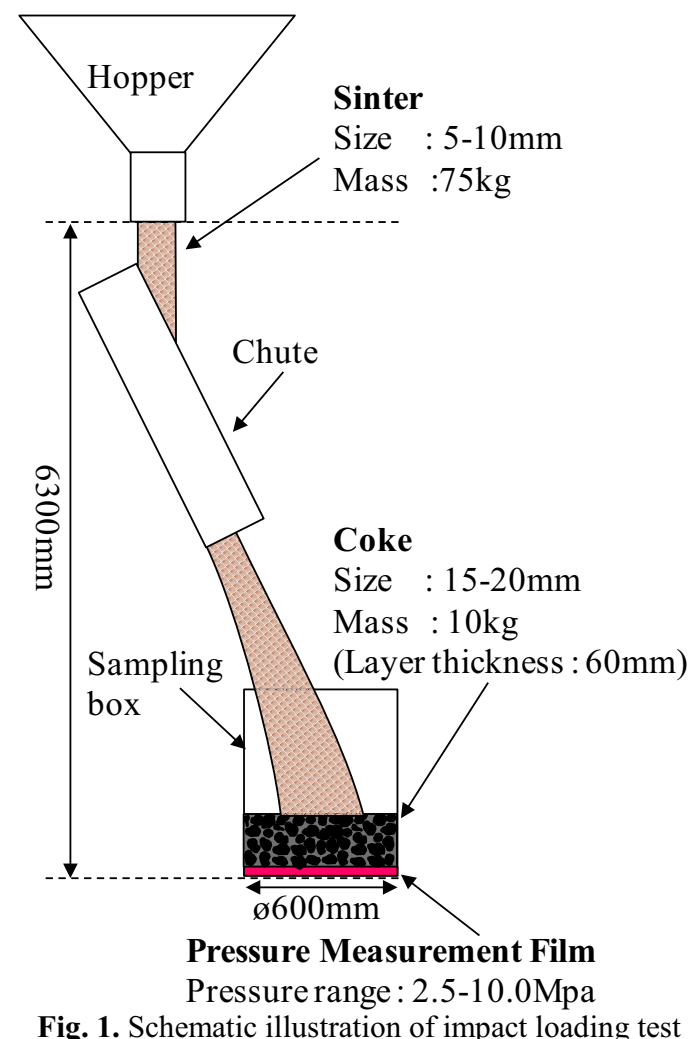

\subsection{Scaled model experiment of ore charging}

The 1/3 scale burden distribution model was used for evaluating the coke collapse(Fig.3). First, the burden was charged to the small bell hopper. Second, the small bell was lowered, and the burden in the small bell hopper dropped on the large bell and stored in the large bell hopper. Third, the large bell was lowered and the burden was discharged into the furnace. By means of repeating this procedure, coke and ore are stacked alternately in layers.

In this study, 1.0 ton of coke having a diameter of $25 \mathrm{~mm}$ or less was stacked in advance. 2.6 ton of ore particle having $3-15 \mathrm{~mm}$ diameter was charged onto coke layer. After charging, the burden in the furnace was collected. The relative thickness of coke was calculated from mass fraction of coke.

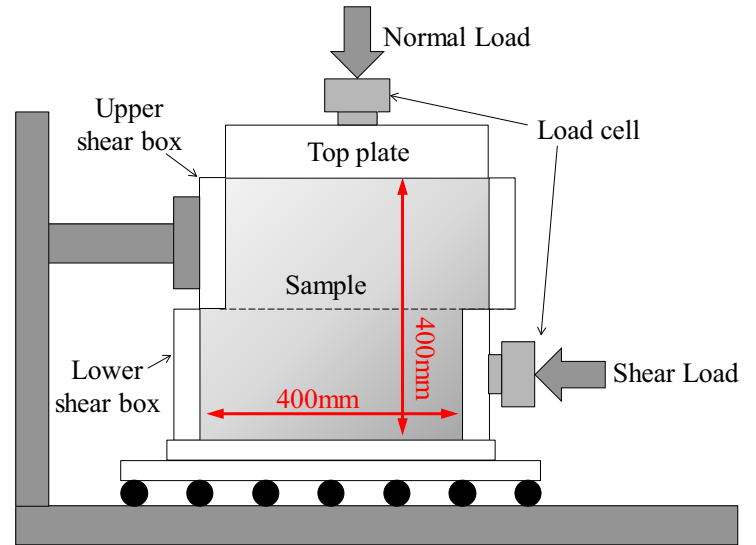

Fig. 2. Schematic illustration of large-scale direct shear test apparatus

Table 1. Experimental conditions. (Large-scale direct shear test)

\begin{tabular}{|c|c|}
\hline Material & Coke \\
\hline Size $[\mathrm{mm}]$ & $19-75$ \\
\hline Samplebox size $[\mathrm{mm}]$ & $400 \times 400 \times 400$ \\
\hline Shear displacement $[\mathrm{mm}]$ & 80 \\
\hline Normal stress $[\mathrm{kPa}]$ & $50,100,150$ \\
\hline
\end{tabular}

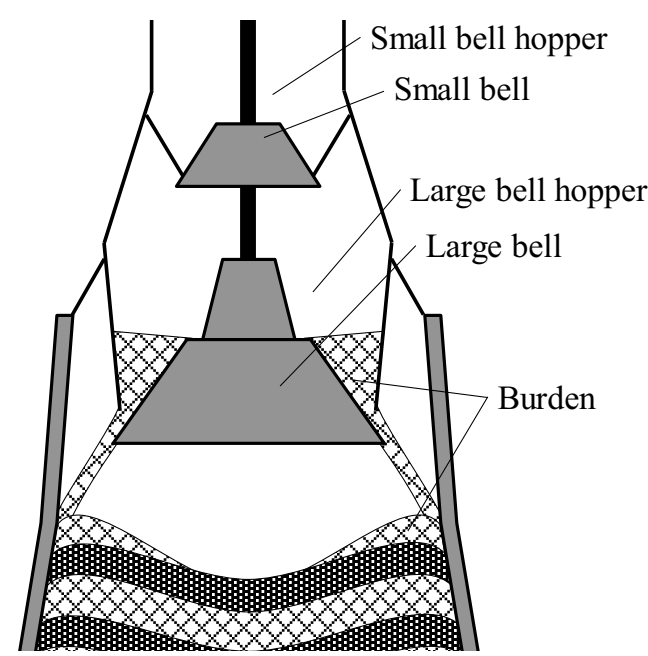

Fig. 3. Schematic illustration of particle flow in the bell top charging system of blast furnace 


\section{Simulation}

\subsection{Discreet Element Method}

DEM is one of the most famous numerical methods for simulating the motion of a large number of particles. Basically, particles are dealt as spheres. The contact forces, which act on each particle, are computed, and then particles' velocity and position are updated within a small time-step. Unlike a continuum analysis of the finite element method, DEM is suitable for analyzing the dynamic behaviour of the individual granular flow. Generally, the simple contact models (Voigt model and Coulomb's friction rule) are used to compute a normal contact force, $\boldsymbol{F}_{\mathrm{n}}$, and a tangential contact Force, $\boldsymbol{F}_{\mathrm{t}}$, as follows.

$$
\begin{aligned}
& \boldsymbol{F}_{\mathrm{n}, \mathrm{ij}}=\left(K_{\mathrm{n}} \Delta u_{\mathrm{n}, \mathrm{ij}}+\eta_{\mathrm{n}} \frac{\Delta u_{\mathrm{n}, \mathrm{ij}}}{\Delta t}\right) \boldsymbol{n}_{\mathrm{ij}} \\
& \boldsymbol{F}_{\mathrm{t}, \mathrm{ij}}=\min \left\{\left[\boldsymbol{F}_{\mathrm{n}, \mathrm{ij}} \mid \boldsymbol{t}_{\mathrm{ij}},\right.\right. \\
& \left.\left[K_{\mathrm{t}}\left(\Delta \boldsymbol{u}_{\mathrm{t}, \mathrm{ij}}+\Delta \boldsymbol{\phi}_{\mathrm{ij}}\right)+\eta_{t}\left(\frac{\Delta \boldsymbol{u}_{\mathrm{t}, \mathrm{ij}}+\Delta \boldsymbol{\phi}_{\mathrm{ij}}}{\Delta t}\right)\right] \boldsymbol{t}_{\mathrm{ij}}\right\}
\end{aligned}
$$

where, $K$ and $\eta$ are the spring and the damping coefficients. $\Delta \boldsymbol{u}$ and $\Delta \phi$ are a relative translational displacement of the gravitational center between two particles and a relative displacement at the contact point

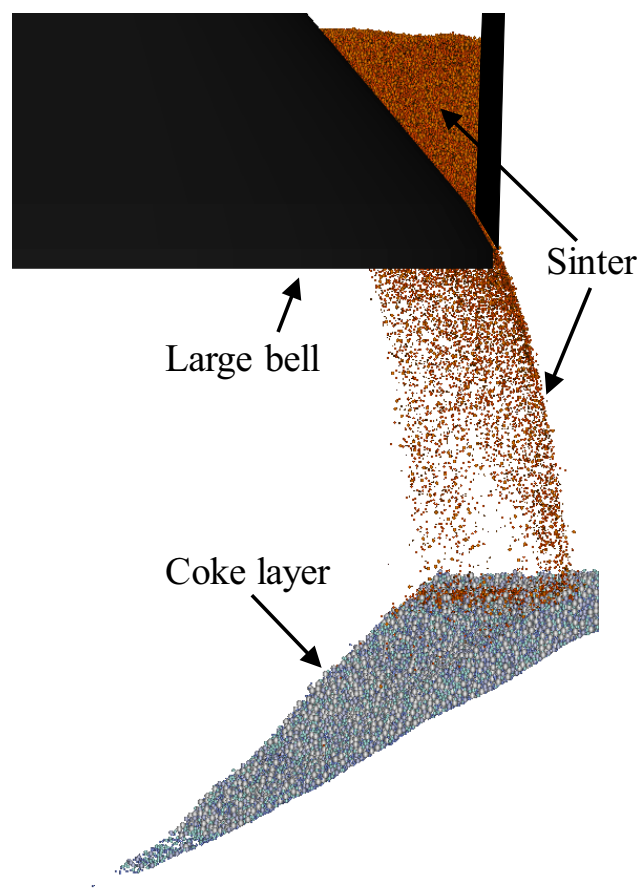

Fig. 4. Simulated charging system.

Table 2. Particle properties used in DEM

\begin{tabular}{|c|c|c|}
\hline & Coke & Ore \\
\hline Diameter $[\mathrm{mm}]$ & $8.5-22.5$ & $4.0-12.5$ \\
\hline Young's modulus $[\mathrm{GPa}]$ & 0.54 & 3.50 \\
\hline Poisson's ratio $[-]$ & 0.22 & 0.25 \\
\hline Particle density $\left[\mathrm{kg} / \mathrm{m}^{3}\right]$ & 1050 & 3300 \\
\hline
\end{tabular}

caused by particle rotation. $\mu$ is the frictional coefficient. $\boldsymbol{n}_{\mathrm{ij}}$ and $\boldsymbol{t}_{\mathrm{ij}}$ denote the unit vector from i-th particle to j-th one in the normal and the tangential components. The subscripts $\mathrm{n}$ and $\mathrm{t}$ also denote the normal and the tangential components.

\subsection{Simulation Setup}

Ore charging behaviour into the $1 / 3$ scale experimental model was simulated by $\operatorname{DEM}($ Fig. 4). The particle properties are tabulated in Table 2. To reduce the computational load, $45^{\circ}$ section of the furnace was simulated and the periodic boundaries were used to enforce the conditions for axi-symmetry in the model.

\section{Results and discussion}

\subsection{Mechanical properties of coke packed bed}

The results of the impact loading test are tabulated in Table 3. The coke particle was broken by the impact stress of ore charging. Pressure measurement film shows that the stress exceeding tensile strength of coke acts on the bottom of coke packed bed.

Fig.5 shows the mass fraction of small particle $(<19 \mathrm{~mm})$ and the shear resistance angle obtained by the large-scale direct shear test. In the case of the normal stress of $50 \mathrm{kPa}$, the coke packed bed has a higher shear resistance angle of $60 \mathrm{deg}$. It indicates that the coke particle is easy to interlock each other and its packed bed has a high shear strength. However, increase of normal steress leads to more breakage of coke particles, and reduction of the shear resistance angle.

Therefore, the impact stress of ore charging lead to coke particle breakage and weaken of shear strength of coke packed bed. Interlocking and breakage of coke particle have a strong influence on the mechanical properties of coke packed bed.

Table 3. Strong stress area on the bottom of sampling box and mass fraction of broken coke particle (impact-loading test).

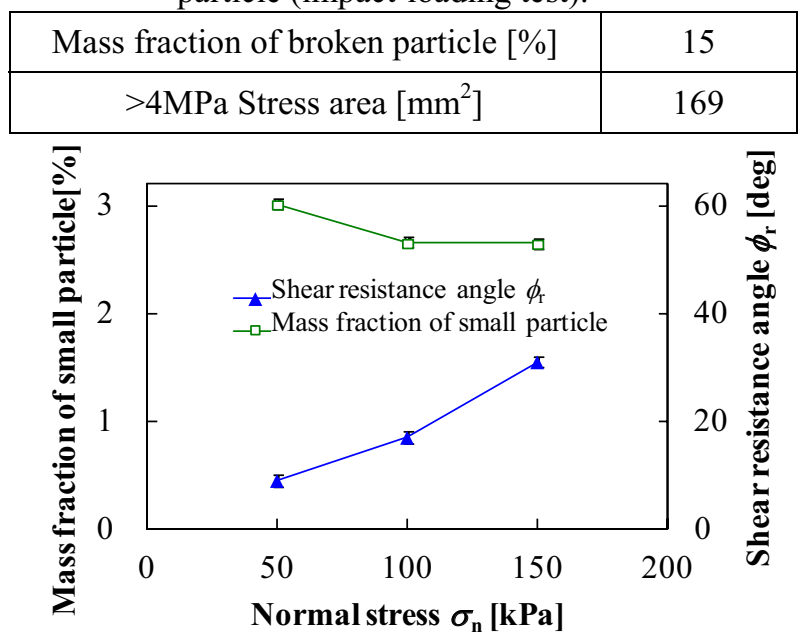

Fig. 5. Increment of fines content and shear resistance angle obtained by large-scale direct shear test 


\subsection{Modification of contact model of DEM}

On the basis of the experimental results, the contact model of DEM was modified to simulate the breakage of particles. In order to simulate weaken of the coke-layer strength under high normal stress, the tangential contact force $\boldsymbol{F}_{\mathrm{t}}$ is modified as follows,

$$
\boldsymbol{F}_{\mathrm{t}, \mathrm{ij}}=\min \left\{\begin{array}{c}
\mu \mathrm{F}_{\mathrm{n}, \max } \boldsymbol{t}_{\mathrm{ij}} \\
\mu\left|\boldsymbol{F}_{\mathrm{n}, \mathrm{ij}}\right| \boldsymbol{t}_{\mathrm{ij}} \\
{\left[K_{\mathrm{t}}\left(\Delta \boldsymbol{u}_{\mathrm{t}, \mathrm{ij}}+\Delta \boldsymbol{\phi}_{\mathrm{ij}}\right)+\eta_{t}\left(\frac{\left.\Delta \boldsymbol{u}_{\mathrm{t}, \mathrm{ij}}+\Delta \boldsymbol{\phi}_{\mathrm{ij}}\right)}{\Delta t}\right)\right] \boldsymbol{t}_{\mathrm{ij}}}
\end{array}\right\}
$$

where, $F_{n, \max }$ is the threshold value of normal contact force which was associated with the strength of coke particle. In this study, $\mathrm{F}_{\mathrm{n}, \max }$ is set at $3 \mathrm{~N} /$ contact. As the result of this modification, the effective friction coefficient $\mu_{\text {eff }}\left(=\left|\boldsymbol{F}_{\mathrm{t}}\right| / \boldsymbol{F}_{\mathrm{n}} \mid\right)$ is decreased under high normal stress as shown in Fig. 6. The frictional coefficient $\mu$ is set at higher value than that of original model in order to simulate the high shear resistance angle caused by the interlocking of particle.

Ore charging behaviour into the blast furnace was simulated by the modified model and the burden distribution was compared with the experimental result. Fig.8 shows the relative coke thickness in radical direction. In comparison with the original, the modified model simulated the thin coke layer near the wall and the thick coke layer in the center of furnace. That indicates the increasing of coke collapse. It is found that the modified model correlated with the experimental result.

\section{Conclusion}

The impact-loading test and the large-scale direct shear test were carried out to investigate the mechanical properties of coke packed bed. Influence of interlocking and breakage on mechanical properties of the packed bed was discussed. The summaries are as follows:

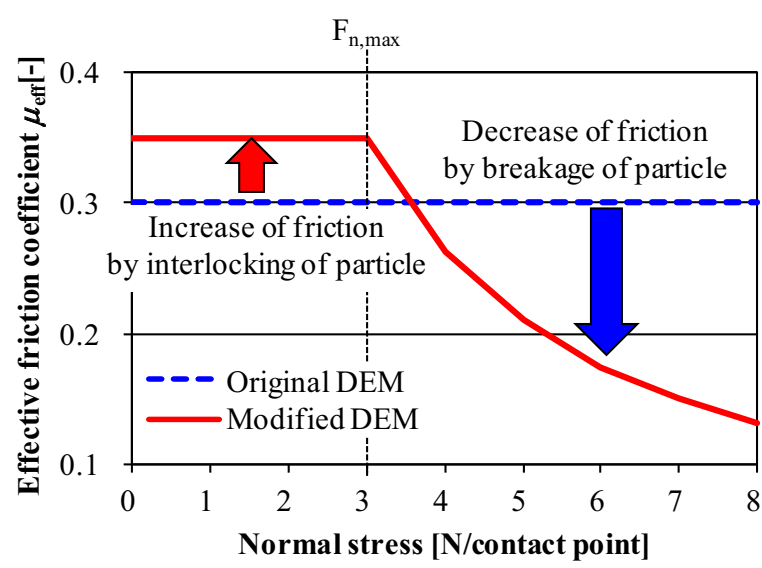

Fig. 6. Effective frictional coefficient of DEM
(1) Under the normal stress of $50 \mathrm{kPa}$ or less, coke packed bed has higher shear strength because coke particles are easy to interlock each other.

(2) Increasing of normal stress leads to weaken of cokelayer strength because of particle breakage.

(3) Breakage of coke particle is also occurred by impact force of ore charging.

Based on the experimental results, the contact force model in DEM was modified to simulate weaken of friction coefficient under high normal stress. The modified DEM correlated with the experimental result.

\section{References}

1. Y. Kajiwara, T. Jimbo, T. Joko, Y. Aminaga and T. Inada: Trans. Iron Steel Inst. Jpn., 24 (1984), 799.

2. Y. Okuno, K. Kunitomo, T. Irita and S. Matsuzaki, Tetsu-to-Hagane 72 (1986) P 783

3. K. Takeda, Y. Konishi, S. Taguchi, and T. Fukutake, Tetsu-to-Hagane 73 (1987) P 282

4. J. Jiminez, J. Mochon, A. Formoso, J. S. Ayala, ISIJ Int., 40 (2000), 114.

5. T. Nouchi, K. Takeda, H. Itaya, Tetsu-to-Hagane 86 (2000) P 293

6. T. Mitra, H. Saxén, ISIJ int., 56 (2016), 1570

7. P. A. Cundall, O. D. L. Strack, Geotechnique, 29 (1979), 47-65.

8. H. Mio, S.Komatsuki, M. Akashi, A. Shimosaka, Y Shirakawa, J. Hidaka, M. Kadowaki, H. Yokoyama, S. Matsuzaki, K. Kunitomo, ISIJ int., 50 (2010), 1000 .

9. T. Nakata, S. Miura, Proc. Jpn. Soc. Civ. Eng., 63 (2007), 224

10. S. Ohtsuka, Y. Konishi, K. Isobe, S. Endo, Jpn. Geotech. J., 10 (2015), 381

11. J. W. Patrick, A. E. Stacey,. Fuel, 51 (1972), 81

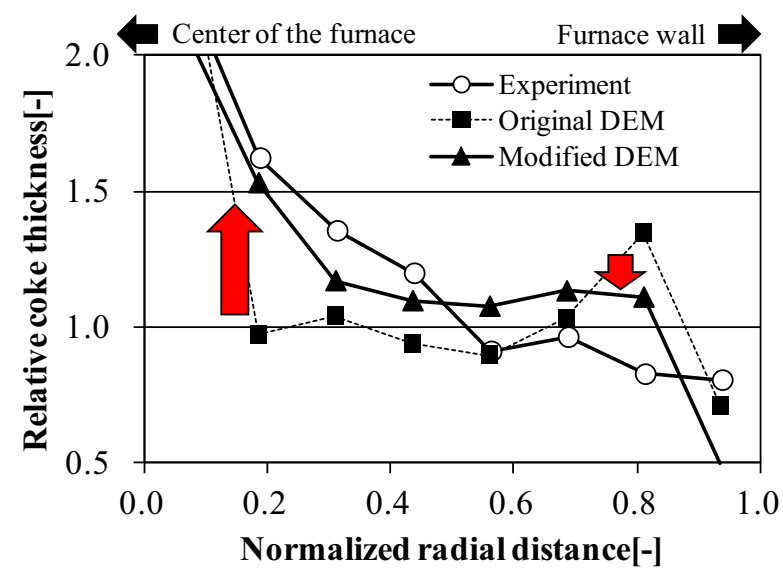

Fig. 7 Relative coke thickness in radical direction. 